\section{Direct oral anticoagulants: A review for the non-specialist}

Thilina Gunawardena

Department of vascular and transplant surgery, National Hospital of Sri Lanka, Colombo, Sri Lanka

\begin{abstract}
Thrombin inhibitors and direct factor Xa inhibitors represent a major breakthrough in the field of anticoagulation pharmacotherapy. These novel agents have replaced warfarin as the oral anticoagulant of choice in certain indications, as they possess equal or superior efficacy and better safety profiles. They have a quick onset of action, predictable pharmacokinetic properties and minimal drug and food interactions. So they do not require frequent blood monitoring and dose adjustments as with warfarin. Considering all the advantages, there seems to be a rapid increase in the number of patients who are started on these novel anticoagulants. In this review, we highlight the pharmacology of these direct oral anticoagulants and the evidence-based indications for their use. We aim to provide a clinical overview for the non-specialist who may be called upon to manage a patient who is currently on one of these novel anticoagulants.
\end{abstract}

\section{Introduction}

For decades warfarin was the only anticoagulant that was available for oral administration. Due to its slow onset of action warfarin still requires some form of parenteral anticoagulation at the start of its therapy. Warfarin has a narrow therapeutic window, so regular monitoring with the international normalized ratio (INR) is essential. As it has numerous food and drug interactions, frequent fluctuations in the INR is a common problem with long term warfarin treatment. Studies have reported that patients who are on warfarin for atrial fibrillation (AF) spend more than half of their treatment duration outside the recommended INR window. ${ }^{1}$ Due to these disadvantages of warfarin, there was a great interest in alternative oral anticoagulants.

Dabigatran was the first successful oral alternative to warfarin. Approval was granted for its use in 2010 as a thromboprophylaxis agent for non-valvular AF. It had numerous advantages over warfarin for patients with AF, such as a quick onset of action that made bridging therapy redundant and the ability to be used at a fixed dose without frequent therapeutic monitoring. After dabigatran, rivaroxaban and apixaban were introduced to the market as oral anticoagulants. Evidence kept accumulating that these drugs were at least as effective as warfarin as anticoagulants with similar or better safety profiles. Considering drug costs alone these new agents are more expensive compared to warfarin. However, when overall costs of treatment are calculated they seem to be more cost-effective to healthcare systems. ${ }^{2,3}$

As a group, these drugs have been referred to as novel oral anticoagulants (NOACs), direct oral anticoagulants (DOACs) and target specific oral anticoagulants (TSOACs). Nonvitamin K oral antagonist is an alternative interpretation for the abbreviation NOAC. To avoid confusion in the nomenclature, the International Society for Thrombosis and Haemostasis has suggested using the term 'direct oral anticoagulants' (DOACs) when referring to these drugs. ${ }^{4}$

DOACs are not recommended for use during pregnancy as available limited data points towards a higher incidence of miscarriages and fetal anomalies. ${ }^{5}$ Randomized clinical trials from the current decade have come up with favorable evidence for using these new drugs in cancer patients with venous thromboembolism (VTE). ${ }^{6-8}$

Standard tests of coagulation, the INR and the activated partial thromboplastin time (APPT) are not reliable indicators to assess the therapeutic effects of DOACs. The drug levels in the body can be measured using sophisticated tests such as chromatography and chromogenic assays but these tests are not readily available in the day-to-day practice of most clinicians. ${ }^{9}$ However, as these drugs possess predictable pharmacokinetics such monitoring is usually not required with their use.

For selected patients who require long term anticoagulation, DOACs may be a better choice than warfarin and this is reflected in current trends of drug prescribing. As for other anticoagulants, bleeding is a major adverse effect of DOACs. With the introduction of specific reversal agents, the options for managing such bleeding induced by DOACs is widening. In this review, we discuss 4 DOACs that are available in the current market, namely dabigatran, rivaroxaban, apixaban and edoxaban, with emphasis on their pharmacology and the evidence base for their use.
Correspondence: Thilina Gunawardena, 12A, Arawwala Road, Pannipitiya, Sri Lanka.

Tel. +94.777030315.

E-mail: thilinamg@gmail.com.

Key words: DOAC; Dabigatran; Rivaroxaban; Apixaban; Edoxaban; Oral anticoagulants.

Conflict of interest: The author declares no potential conflict of interest.

Funding: None.

Ethics approval: Not applicable.

Consent for publication: Not applicable.

Availability of data and materials: All data generated or analyzed during this study are included in this published article.

Received for publication: 30 April 2021.

Revision received: 21 May 2021.

Accepted for publication: 2 September 2021.

This work is licensed under a Creative Commons Attribution-NonCommercial 4.0 International License (CC BY-NC 4.0).

${ }^{C}$ Copyright: the Author(s), 2021

Licensee PAGEPress, Italy

Hematology Reports 2021; 13:9239

doi:10.4081/hr.2021.9239

\section{Dabigatran}

Dabigatran was approved by the FDA in 2010 for the use of thromboprophylaxis in non-valvular AF. At present, its use has expanded to cover the management of VTE as well. It is administered as a pro-drug dibigatran etexilate, which is rapidly converted to the active form dabigatran after absorption. Dabigatran is a direct reversible inhibitor of thrombin and acts on both free and fibrin-bound thrombin. ${ }^{10,11}$

Following its administration, dabigatran will take 0.5-2 hours to reach maximum plasma concentrations. ${ }^{10}$ Eighty percent of the absorbed drug is excreted by the kidneys so dose reductions are necessary for those with renal impairment. Full therapeutic doses can be given when the creatinine clearance $(\mathrm{CrCl})$ is $>50 \mathrm{~mL} / \mathrm{min}$ and dose reductions should be considered when the $\mathrm{CrCl}$ is between $30-50 \mathrm{~mL} / \mathrm{min}$. Dabigatran is not recommended when the $\mathrm{CrCl}$ is $<30$ $\mathrm{mL} / \mathrm{min}$ or in dialysis-dependent patients. ${ }^{12}$

Dabigatran is not metabolized by the cytochrome p450 enzymes of the liver, so food and drug interactions are not as common as with warfarin. However, it is a substrate for p-glycoprotein, a cell membranebound drug efflux pump. Drug interactions 
may occur when dabigatran is co-administered with agents that induce or inhibit the p-glycoprotein system. ${ }^{10,11}$ Dabigatran is said to be safe in mild to moderate liver disease but its use is not recommended when there is severe liver impairment. Bleeding and known hypersensitivity to the drug are contraindications for its use. Common side effects are bleeding and gastric irritation. ${ }^{10}$

INR and APPT may be prolonged in those who are taking dabigatran, but these changes do not truly reflect its therapeutic effects. In fact, for the INR to become abnormal in a patient who is on dabigatran, the serum concentrations of the drug should be 3-4 times above the recommended safe therapeutic levels. ${ }^{13}$ In overdose, absorption of the drug can be limited by administration of activated charcoal within the first 2-3 hours of ingestion. As dabigatran is minimally bound to proteins, hemodialysis (HD) is an effective intervention to remove the drug from the circulation. Idarucizumab is a specific antidote developed against dabigatran. It binds to the thrombin binding site of the dabigatran molecule with a much higher affinity than thrombin. ${ }^{9}$ The REVERSE Ad trial which assessed the efficacy of this antidote concluded that it is safe and effective. ${ }^{14}$ Prothrombin concentrate, tranexamic acid and desmopressin are acceptable alternatives when dealing with a patient who needs rapid reversal of dabigatran. However, fresh frozen plasma (FFP) is not recommended for this indication. ${ }^{13}$

\section{Clinical trials and indications}

The RE-LY trial compared the efficacy of dabigatran against warfarin for the prevention of embolic stroke in patients with non-valvular AF. At a dose of $110 \mathrm{mg}$ twice daily dabigatran was as effective as warfarin with a reduced risk of major bleeding. When dabigatran was given $150 \mathrm{mg}$ twice daily its ability to prevent stroke was superior to warfarin and the risk of major bleeding between the two drugs was similar. ${ }^{15}$

The RE-COVER trial which was published in 2009 compared fixed-dose dabigatran against INR adjusted warfarin for the treatment of acute symptomatic venous thromboembolic disease. All patients recruited for the study were initially treated with heparin or enoxaparin before being randomized to receive dabigatran $150 \mathrm{~g}$ twice daily or warfarin. According to the findings of this study, fixed-dose dabigatran was as effective and safe as warfarin for the treatment of acute deep vein thrombosis (DVT) or pulmonary embolism (PE). ${ }^{16}$

RE-SONATE study evaluated the suit- ability of dabigatran as a long-term anticoagulant for preventing recurrent venous thromboembolism (VTE) in high-risk patients. Patients who had completed 3 months of anticoagulation for proximal DVT or PE and were considered to have a high risk of recurrent VTE were recruited for the study. They were randomized to receive either dabigatran $150 \mathrm{mg}$ twice daily or warfarin (titrated to achieve an INR of 2-3) for 6-18 months. Dabigatran was found to be as effective as warfarin for the prevention of recurrent VTE in these patients with a lower risk of bleeding. ${ }^{17}$

RE-MODEL and the RE-NOVATE trials compared dabigatran against enoxaparin as a pharmacological prophylactic agent for VTE after total knee and total hip replacement respectively. Both trials concluded that dabigatran was as efficacious as enoxaparin and had a similar safety profile. ${ }^{18,19}$

The RE-ALIGN study explored the possibility of using dabigatran in patients with mechanical heart valves, but the study had to be terminated prematurely due to the higher incidence of stroke and bleeding noted in the dabigatran treated group compared to those treated with warfarin. ${ }^{20}$ After the dismal findings of this study, DOACs have been contraindicated in patients with prosthetic heart valves. However, some argue that withholding DOACs in this group of patients based on the findings of a single study is irrational and further welldesigned studies are warranted to shed light on this grey area. ${ }^{21}$

\section{Rivaroxaban}

Rivaroxaban, a direct inhibitor of factor Xa was approved in 2011 for the prevention of thromboembolism in non-valvular $\mathrm{AF}$ and as a prophylactic agent for DVT in post hip/knee arthroplasty patients. ${ }^{10}$ Unlike the heparins which require antithrombin III for their action, rivaroxaban is independent of this cofactor. Although factor Xa bound to thrombin is inaccessible to heparins, rivaroxaban acts on bound factor $\mathrm{Xa}$ as well, so it may be more effective in preventing clot propagation. ${ }^{3}$

The drug is rapidly absorbed after oral administration and peak plasma concentrations can be expected in 2-4 hours. Doses of $15 \mathrm{mg}$ or above should be taken with meals. ${ }^{3,10}$ One third of the drug is excreted unchanged by the kidneys and the rest is metabolized in the liver by the cytochrome p 450 enzymes. The metabolized drug is excreted via urine and bile. Being a substrate for cytochrome enzymes and the pglycoprotein membrane efflux channel, rivaroxaban will have drug interactions with inducers and inhibitors of these two systems. $^{3}$

Dose reduction should be considered when rivaroxaban is prescribed for patients with renal impairment when the $\mathrm{CrCl}$ is 50 $15 \mathrm{~mL} / \mathrm{min}^{12}$ It can be used safely in Child's A liver disease. Rivaroxaban is not recommended for use when the $\mathrm{CrCl}$ is $<15$ $\mathrm{mL} / \mathrm{min}$ or in moderate or severe (Child's B and C) liver disease.

Absolute contraindications for the use of rivaroxaban are active bleeding and known hypersensitivity to the drug. Bleeding is the most common side effect. Headache, diarrhea or constipation, abdominal pain, limb oedema and elevation of liver transaminases are the other minor side effects that have been reported with its use. ${ }^{10}$

Rivaroxaban may cause a rise in the INR and APTT, but these tests are not accurate indicators of its therapeutic effect. In rivaroxaban overdose, activated charcoal can be used to limit absorption. However, it should be used within 8 hours of drug ingestion. ${ }^{10}$ As close to $95 \%$ of the drug is protein bound, HD is not effective in rivaroxaban overdose. ${ }^{9}$ Andexanet alfa is a recently introduced antidote for the management of life-threatening bleeding caused by factor $\mathrm{Xa}$ inhibitors. It is a structural analogue of factor $\mathrm{Xa}$ and binds to direct factor $\mathrm{Xa}$ inhibitors and antithrombin bound heparin, effectively blocking their anticoagulant effect. Due to its short half-life andexanet needs to be given as a continuous infusion until desired haemostasis is achieved..$^{9,22}$ When andexanet alfa is not available, prothrombin concentrate, tranexamic acid and desmopressin are useful alternatives for reversing the effects of rivaroxaban. ${ }^{13}$

\section{Clinical trials and indications}

Rivaroxaban $v s$ warfarin in nonvalvular atrial fibrillation (ROCKET AF) trial was a non-inferiority trial that compared oncedaily rivaroxaban at a dose of $20 \mathrm{mg}$ against INR adjusted warfarin for thromboprophylaxis in nonvalvular AF. The study concluded that rivaroxaban was as effective as warfarin for this indication with less risk of intracranial and other fatal bleeds. ${ }^{23}$

EINSTEIN DVT and EINSTEIN PE trials provided evidence that rivaroxaban had equal efficacy to warfarin with regards to prevention of recurrent VTE when used on a short-term basis for acute DVT and PE. Both studies used rivaroxaban at a dose of $15 \mathrm{mg}$ twice daily for 3 weeks followed by $20 \mathrm{mg}$ once daily for 3-12 months dura- 
tion. ${ }^{24,25}$ The extension of the EINSTEIN DVT study compared continued therapy with rivaroxaban $20 \mathrm{mg}$ daily against placebo for a further 6-12 months in patients who had completed 6-12 months therapy of anticoagulation for venous thromboembolic disease. The group treated with rivaroxaban had fewer episodes of recurrent VTE with a non-fatal major bleeding risk of $0.7 \%{ }^{24}$ So rivaroxaban appears to be an efficacious agent with an acceptable safety profile for continuous treatment of patients at a high risk of recurrent VTE.

Antiphospholipid syndrome (APLS) is an autoimmune disorder that predisposes to thromboembolism and adverse pregnancy outcomes. A study published in 2018 compared rivaroxaban $20 \mathrm{mg}$ (15 $\mathrm{mg}$ in renal impairment) once daily against warfarin (INR target 2.5) in patients with high-risk APLS. High-risk APLS was defined as triple positivity for lupus anticoagulant, anti-cardiolipin and anti- $\beta 2$-glycoprotein I antibodies. The study had to be stopped prematurely as patients on the rivaroxaban arm had increased thromboembolic and bleeding events. ${ }^{26}$ These findings have led to recent guidelines recommending against the use of DOACs in patients with APLS. ${ }^{27}$

The recently published SELECT D study compared low molecular weight heparin (LMWH) and rivaroxaban for the prevention of recurrent thromboembolic events in cancer patients with acute PE or proximal DVT. Patients were randomized to receive either dalteparin (dose adjusted according to body weight) or rivaroxaban (15 $\mathrm{mg}$ twice a day for 3 weeks followed by $20 \mathrm{mg}$ daily). The total duration of treatment was 6 months. The group given rivaroxaban had fewer recurrent VTE events. The incidence of major bleeding was not different among the 2 groups but rivaroxaban treated patients had a higher incidence of clinically significant nonmajor bleeding events. ${ }^{6}$

The efficacy of rivaroxaban as a thromboprophylaxis agent after arthroplasty was proven by the RECORD trials. As per the results of RECORD 1 and 2 studies, oncedaily rivaroxaban $10 \mathrm{mg}$ was superior to subcutaneous enoxaparin in preventing thromboembolism after total hip arthroplasty with a similar risk of bleeding. ${ }^{28,29}$ According to RECORD 3 and 4 trials, rivaroxaban $10 \mathrm{mg}$ once daily proved to be more effective than subcutaneous enoxaparin after total knee arthroplasty as a pharmacological thromboprophylaxis agent. ${ }^{30,31}$

The COMPASS trial was a randomized controlled clinical trial published in 2017 which evaluated the efficacy of rivaroxaban as an agent for secondary prevention of adverse cardiovascular events in patients with stable atherosclerosis. Study participants were randomized into 3 groups. One group was given aspirin $100 \mathrm{mg}$ daily. The second and third groups received rivaroxaban $5 \mathrm{mg}$ twice daily or aspirin $100 \mathrm{mg}$ daily plus rivaroxaban $2.5 \mathrm{mg}$ twice daily. Rivaroxaban plus aspirin was found to be better at preventing secondary cardiovascular events at the cost of more major bleeding. Rivaroxaban alone was not more efficacious than aspirin but had more bleeding events. $^{32}$ The VOYAGER PAD study recruited 6564 patients who have undergone lower extremity revascularization procedures and randomized them to receive rivaroxaban $2.5 \mathrm{mg}$ twice daily and aspirin or aspirin plus placebo. The study aimed to study the efficacy of adding rivaroxaban to aspirin in preventing adverse limb events (acute limb ischaemia and major amputations), myocardial infarction, ischaemic stroke or death due to cardiovascular events. The study found out that the addition of rivaroxaban was effective in reducing the incidence of all these adverse endpoints. The incidence of major bleeding events in the rivaroxaban treated group was higher when major bleeding was defined as per the International Society on Thrombosis and Haemostasis criteria. ${ }^{33}$

\section{Apixaban}

Apixaban is a direct factor Xa inhibitor with a similar mechanism of action to rivaroxaban. It was approved in 2012 for VTE prophylaxis after total hip or knee arthroplasty. After oral administration, the drug is rapidly absorbed and maximum plasma concentrations are achieved in 1-3 hours. ${ }^{3}$ The drug is metabolized by the liver and the kidney and mainly excreted by the liver. As apixaban is a substrate for the cytochrome p450 enzymes drug interaction should be expected when patients are concurrently on inducers or inhibitors of this enzyme system. Apixaban is not recommended in patients with severe liver disease or end stage kidney disease. It can be used with caution when there is mild to moderate liver impairment. When the $\mathrm{CrCl}$ is $15-30$ $\mathrm{mL} / \mathrm{min}$ the apixaban dose should be reduced. ${ }^{12}$

Active bleeding and known hypersensitivity to apixaban are contraindications for its use. The commonly reported side effects are bleeding, nausea, vomiting and elevation of liver enzymes. ${ }^{10}$

As with other DOACs, apixaban may prolong APTT and INR but these tests are not used for monitoring its therapeutic effect. In apixaban overdose activated char- coal can be given within 6 hours to reduce gut absorption. As most of the drug in the systemic circulation is protein-bound, dialysis is not a useful option for managing overdose. Andexanet alfa is an effective antidote to reverse the effects of apixaban. As for other DOACs, FFP is not a recommended agent to counteract the action of this drug. However, prothrombin concentrate, tranexamic acid and desmopressin can be used for the rapid reversal of apixaban..$^{9,13}$

\section{Clinical trials and indications}

Apixaban $v s$ warfarin in patients with atrial fibrillation (ARISTOTLE) trial compared apixaban $5 \mathrm{mg}$ twice daily against INR-adjusted warfarin in patients with atrial fibrillation. According to study conclusions, apixaban was superior to warfarin in preventing stroke and other embolic phenomena in patients with AF. The incidence of bleeding was also less. ${ }^{34}$

The AVERROES study recruited patients with AF with a high risk of thromboembolism, who were not suitable for warfarin therapy. They were randomized to receive either apixaban $5 \mathrm{mg}$ twice daily or aspirin and followed up. The study had to be terminated prematurely as apixaban had a clear advantage in these patients for prevention of stroke and other systemic embolic phenomena without increasing major bleeding episodes. ${ }^{35}$

ADVANCE 1 trial was a non-inferiority trial that compared apixaban against subcutaneous enoxaparin for VTE prophylaxis after total knee replacement. Patients were randomized to receive either apixaban 2.5 $\mathrm{mg}$ twice daily or enoxaparin $30 \mathrm{mg}$ twice daily for a total duration of 10-14 days after the surgery. Those who received apixaban had fewer bleeding manifestations but the drug did not meet the predefined non-inferiority criteria set out in the study protocol. ${ }^{36}$ In the ADVANCE 2 trial, post knee arthroplasty patients were given apixaban $2.5 \mathrm{mg}$ twice daily or a single daily dose of enoxaparin $40 \mathrm{mg}$ for 10-14 days following surgery. Apixaban at the given dose was found to be more effective in preventing VTE compared to once-daily enoxaparin without an increase in bleeding events. ${ }^{37}$

ADVANCE 3 trial evaluated apixaban $2.5 \mathrm{mg}$ twice daily vs enoxaparin $40 \mathrm{mg}$ once daily for VTE prophylaxis in patients who have undergone hip arthroplasty. Both drugs were continued for 35 days postsurgery. The incidence of VTE was significantly less in the apixaban treated group while the risk of bleeding was similar between the 2 groups. ${ }^{38}$ 
The AMPLIFY investigators studied the efficacy and safety of apixaban as a therapeutic agent for acute VTE. They randomized patients with DVT or PE to receive apixaban or conventional therapy with warfarin bridged with enoxaparin. The apixaban treatment arm received $10 \mathrm{mg}$ of the drug twice a day for 7 days followed by 5 mg twice a day for 6 months. The DOAC was found to be non-inferior to warfarin for the prevention of recurrent VTE events with a lesser risk of bleeding episodes. ${ }^{39}$ As per the results of AMPLIFY-EXT study, continuing treatment with apixaban at a therapeutic dose of $5 \mathrm{mg}$ twice a day or at a prophylactic dose of $2.5 \mathrm{mg}$ twice a day in patients who had completed 6-12 months of anticoagulant therapy for a proven episode of VTE was associated with a reduction of recurrent thromboembolic events. It was noted that there was no increase in the risk of major bleeding when such extended treatment was continued. However, the patients in the study who received such long-term anticoagulation were not a highrisk group for recurrent VTE. ${ }^{40}$
Apixaban is a DOAC that has proven efficacy for the use in patients with cancerassociated VTE. According to results published by the Caravaggio Investigators, when apixaban was compared to subcutaneous dalteparin in patients with cancer and proximal DVT or PE, the DOAC was noninferior to the LMWH for the prevention of recurrent thrombo-embolic episodes without increasing the risk of bleeding. ${ }^{7}$ The dosing of apixaban used in this study was as same as in the AMPLIFY study. ${ }^{39}$

\section{Edoxaban}

Edoxaban is another direct factor $\mathrm{Xa}$ inhibitor approved by the FDA in 2015. It is currently approved for use in patients with non-valvular AF and VTE. After oral administration edoxaban takes 1-2 hours to reach peak plasma concentrations. Fifty percent of the drug is excreted by the kidneys unchanged. Small amounts are metabolized by the cytochrome $\mathrm{p} 450$ enzymes in the liver. It is a substrate for $\mathrm{p}$ glycoprotein efflux pump as well. Drug interactions can occur with inducers or inhibitors of these two systems. The drug appears safe in mild to moderate liver disease. Renal impairment will significantly alter its pharmacokinetics, so dose adjustments are necessary. ${ }^{10,41}$ Current guidelines recommend halving the dose of edoxaban when the $\mathrm{CrCl}$ is between $15-50 \mathrm{~mL} / \mathrm{min}$ and avoiding it when the $\mathrm{CrCl}$ is $<15 \mathrm{~mL} / \mathrm{min}^{12}$

Standard tests of coagulation, the INR and the APTT can be prolonged when taking edoxaban, but the effects of the drug on these tests are unpredictable and small, so they are not useful for therapeutic monitoring. ${ }^{36}$ In overdose, it is unclear whether activated charcoal or haemodialysis is of benefit. Being a factor $\mathrm{Xa}$ antagonist, andexanet alfa can be used for reversing the effects of this drug. ${ }^{9}$

\section{Trials and indications}

The ENGAGE AF TIMI 48 trial compared edoxaban versus warfarin for the prevention of embolic complications in

Table 1. Summary of indications and dosing for direct oral anticoagulants in otherwise healthy individuals and those with renal impairment (dabigatran is contraindicated when the creatinine clearance $(\mathrm{CrCl})$ is $<30 \mathrm{~mL} / \mathrm{min}$, rivaroxaban, apixaban and edoxaban are contraindicated when the $\mathrm{CrCl}$ is $<15 \mathrm{~mL} / \mathrm{min}$ ).

\begin{tabular}{|c|c|c|c|}
\hline Drug & Indication & Dosage in otherwise healthy individuals & Dosage in renal impairment \\
\hline \multirow[t]{4}{*}{ Dabigatran } & $\begin{array}{l}\text { Prevention of stroke and systemic } \\
\text { embolism in non-valvular AF }\end{array}$ & 150 mg twice daily & $\begin{array}{l}\text { When } \mathrm{CrCl} \text { is } 30-50 \mathrm{~mL} / \mathrm{min} \text { use } 110 \mathrm{mg} \\
\text { twice daily }\end{array}$ \\
\hline & Treatment of acute VTE & $\begin{array}{l}150 \mathrm{mg} \text { twice daily (after at least } 5 \text { days of } \\
\text { parenteral anticoagulants) }\end{array}$ & $\begin{array}{l}\text { When CrCl is } 30-50 \mathrm{~mL} / \mathrm{min} \text { use } 110 \mathrm{mg} \\
\text { twice daily (after at least } 5 \text { days of } \\
\text { parenteral anticoagulants) }\end{array}$ \\
\hline & $\begin{array}{l}\text { Extended treatment for prevention } \\
\text { of recurrent VTE in high-risk individuals }\end{array}$ & 150 mg twice daily & $\begin{array}{l}\text { When } \mathrm{CrCl} \text { is } 30-50 \mathrm{~mL} / \mathrm{min} \text { use } 110 \mathrm{mg} \\
\text { twice daily }\end{array}$ \\
\hline & Thromboprophylaxis after THR/ TKR & 150 mg once daily & $\begin{array}{l}\text { When CrCL is } 30-50 \mathrm{~mL} / \mathrm{min} \text { initial dose of } \\
75 \mathrm{mg} \text { followed by } 150 \mathrm{mg} \text { daily }\end{array}$ \\
\hline \multirow[t]{4}{*}{ Rivaroxaban } & $\begin{array}{l}\text { Prevention of stroke and systemic } \\
\text { embolism in non-valvular AF }\end{array}$ & $\begin{array}{l}20 \mathrm{mg} \text { once daily } \\
\text { once daily }\end{array}$ & When $\mathrm{CrCl}$ is $15-50 \mathrm{~mL} / \mathrm{min}$ use $15 \mathrm{mg}$ \\
\hline & Treatment of acute VTE & $\begin{array}{l}15 \mathrm{mg} \text { twice daily for } 3 \text { weeks, } \\
\text { then } 20 \text { mg once daily }\end{array}$ & $\begin{array}{l}\text { When } \mathrm{CrCl} \text { is } 15-50 \mathrm{~mL} / \mathrm{min} \text { use } 15 \mathrm{mg} \\
\text { twice daily for } 3 \text { weeks and consider a } \\
\text { reduced dose of } 15 \mathrm{mg} \text { daily thereafter }\end{array}$ \\
\hline & $\begin{array}{l}\text { Extended treatment for prevention } \\
\text { of recurrent VTE }\end{array}$ & 20 mg once daily & $\begin{array}{l}\text { When } \mathrm{CrCl} \text { is } 15-50 \mathrm{~mL} / \mathrm{min} \text { consider a } \\
\text { reduced dose of } 15 \mathrm{mg} \text { daily }\end{array}$ \\
\hline & Thromboprophylaxis after THR/ TKR & 10 mg once daily & $\begin{array}{l}\text { When } \mathrm{CrCl} 15-50 \mathrm{~mL} / \mathrm{min} \text { use } 10 \mathrm{mg} \\
\text { once daily }\end{array}$ \\
\hline \multirow[t]{3}{*}{ Apixaban } & $\begin{array}{l}\text { Prevention of stroke and systemic } \\
\text { embolism in non-valvular AF }\end{array}$ & 5 mg twice daily & $\begin{array}{l}\text { When } \mathrm{CrCl} \text { is } 15-50 \mathrm{~mL} / \mathrm{min} \text { use } 2.5 \mathrm{mg} \\
\text { twice daily } \\
\text { When creatinine is }>133 \mu \mathrm{mol} / \mathrm{L} \text { with age } \\
80 \text { years or above Or weight }<60 \mathrm{~kg} \text { use } \\
2.5 \mathrm{mg} \text { twice daily }\end{array}$ \\
\hline & Treatment of VTE & $\begin{array}{l}10 \mathrm{mg} \text { twice daily for } 7 \text { days, } \\
\text { then } 5 \mathrm{mg} \text { twice daily }\end{array}$ & $\begin{array}{l}\text { When } \mathrm{CrCl} \text { is } 15-50 \mathrm{~mL} / \mathrm{min} \text { use } 10 \mathrm{mg} \\
\text { twice daily for } 7 \text { days, then } 5 \mathrm{mg} \text { twice } \\
\text { daily, with caution }\end{array}$ \\
\hline & Thromboprophylaxis after THR/ TKR & $2.5 \mathrm{mg}$ twice daily & $\begin{array}{l}\text { When } \mathrm{CrCl} \text { is } 15-50 \mathrm{~mL} / \mathrm{min} \text { use } 2.5 \mathrm{mg} \\
\text { twice daily, with caution }\end{array}$ \\
\hline \multirow[t]{2}{*}{ Edoxaban } & $\begin{array}{l}\text { Prevention of stroke and systemic } \\
\text { embolism in non-valvular AF }\end{array}$ & 60 mg daily & $\begin{array}{l}\text { When } \mathrm{CrCl} \text { is } 15-50 \mathrm{~mL} / \mathrm{min} \text { use } 30 \mathrm{mg} \\
\text { once a day }\end{array}$ \\
\hline & Treatment of VTE & $\begin{array}{l}60 \text { mg daily (after at least } 5 \text { days of } \\
\text { parenteral anticoagulants) }\end{array}$ & $\begin{array}{l}\text { When } \mathrm{CrCl} \text { is } 15-50 \mathrm{~mL} / \mathrm{min} 30 \mathrm{mg} \text { once } \\
\text { a day (after at least } 5 \text { days of parenteral } \\
\text { anticoagulants) }\end{array}$ \\
\hline
\end{tabular}

AF, atrial fibrillation; $\mathrm{CrCl}$, creatinine clearance; VTE, venous thromboembolism; THR, total hip replacement; TKR, total knee replacement. 
patients with non-valvular AF. Edoxaban was given as a low dose $(30 \mathrm{mg} /$ day $)$ or a high dose $(60 \mathrm{mg} /$ day $)$. Both regimens of edoxaban were non-inferior to warfarin in preventing systemic embolism and had fewer bleeding complications as well as fewer cardiovascular deaths. ${ }^{42}$

Edoxaban was explored as a treatment option for acute VTE by the Hokusai VTE investigators. In their randomized controlled clinical trial, they compared edoxaban against warfarin and concluded that edoxaban was non-inferior to warfarin when given for patients with acute DVT or PE for the prevention of recurrent VTE. The lesser bleeding risk associated with edoxaban was an additional advantage. Patients in both treatment arms of this study were initially treated with heparin. Edoxaban was given at a dose of $60 \mathrm{mg} /$ day or at a reduced dose of $30 \mathrm{mg} /$ day when the $\mathrm{CrCl}$ was 30 $50 \mathrm{~mL} / \mathrm{min}$ or when the body weight was $<60 \mathrm{~kg}$. Warfarin dose was titrated to achieve a target INR of $2-3 .{ }^{43}$ A post-hoc analysis of the same study compared the efficacy and safety of continuing treatment with either agent up to 12 months. The dosing protocols for edoxaban and warfarin were similar to the 3-month study. As per the results of this post-hoc analysis, once daily edoxaban was an acceptable alternative to warfarin for extended treatment in patients with a history of VTE. ${ }^{44}$

According to a different study by the Hokusai VTE Cancer investigators, oral edoxaban was found to be a non-inferior alternative to LMWH with regards to efficacy and safety when used in cancer patients with acute VTE. Patients with cancer and a concomitant diagnosis of acute PE or proximal DVT were randomized to 2 groups that received either weight-adjusted dalteparin or edoxaban for a total duration of 6-12 months. Edoxaban was given at a dose of 60 $\mathrm{mg}$ /day following a course of LMWH for 5 days. The edoxaban treated group had fewer recurrent thrombo-embolic episodes at the cost of more major bleeding events. ${ }^{8}$

\section{Discussion and conclusions}

With their proven efficacy and safety profiles, DOACs represent an attractive alternative to warfarin for selected patients who have an indication for long term anticoagulation. Their quick onset of action, limited drug interactions and predictable therapeutic effects make them a more convenient choice compared to warfarin. Recent guidelines recommended DOACs as the first line anticoagulants for the treatment of provoked proximal DVT and non- valvular AF. ${ }^{27,45}$ The available armamentarium for the management of DOAC induced bleeding is expanding. As DOACs are becoming more mainstream, clinicians are more likely to encounter patients who are on these agents. The knowledge on pharmacology, side effects and dosing of these novel anticoagulants becomes useful when managing such patients as well as in prescribing these agents for patients more suited for DOAC based anticoagulation.

\section{References}

1. Baker WL, Cios DA, Sander SD, Coleman CI. Meta-analysis to assess the quality of warfarin control in atrial fibrillation patients in the United States. J Manag Care Pharm 2009;15:244-52.

2. Deitelzweig S, Amin A, Jing Y, et al. Medical cost reductions associated with the usage of novel oral anticoagulants vs warfarin among atrial fibrillation patients, based on the RE-LY, ROCKET-AF, and ARISTOTLE trials. J Med Econ 2012;15:776-85.

3. Harder S, Graff J. Novel oral anticoagulants: clinical pharmacology, indications and practical considerations. Eur J Clin Pharmacol 2013;69:1617-33.

4. Barnes GD, Ageno W, Ansell J, Kaatz $\mathrm{S}$; Subcommittee on the control of anticoagulation of the International Society on Thrombosis and Haemostasis. Recommendation on the nomenclature for oral anticoagulants: communication from the SSC of the ISTH. J Thromb Haemost 2015;13:1154-6.

5. Lameijer H, Aalberts JJJ, van Veldhuisen DJ, et al. Efficacy and safety of direct oral anticoagulants during pregnancy; a systematic literature review. Thromb Res 2018;169:123-7.

6. Young AM, Marshall A, Thirlwall J, et al. Comparison of an oral factor $\mathrm{Xa}$ inhibitor with low molecular weight heparin in patients with cancer with venous thromboembolism: results of a randomized trial (SELECT-D). J Clin Oncol 2018;36:2017-23.

7. Agnelli G, Becattini C, Meyer G, et al. Apixaban for the treatment of venous thromboembolism associated with cancer. N Engl J Med 2020;382:1599-607.

8. Raskob GE, van Es N, Verhamme P, et al. Edoxaban for the treatment of cancer-associated venous thromboembolism. N Engl J Med 2018;378:61524.

9. Crowther M, Crowther MA. Antidotes for novel oral anticoagulants: current status and future potential. Arterioscler Thromb Vasc Biol 2015;35:1736-45.
10. Wanat MA. Novel oral anticoagulants: a review of new agents. Postgrad Med 2013;125:103-14.

11. Blommel ML, Blommel AL. Dabigatran etexilate: a novel oral direct thrombin inhibitor. Am J Health Syst Pharm 2011;68:1506-19.

12. Parker K, Thachil J. The use of direct oral anticoagulants in chronic kidney disease. Br J Haematol 2018;183:17084.

13. Christos S, Naples R. Anticoagulation reversal and treatment strategies in major bleeding: update 2016. West J Emerg Med 2016;17:264-70.

14. Pollack CV Jr, Reilly PA, van Ryn J, et al. Idarucizumab for dabigatran reversal - full cohort analysis. N Engl J Med 2017;377:431-41.

15. Connolly SJ, Ezekowitz MD, Yusuf S, et al. RE-LY Steering Committee and Investigators. Dabigatran versus warfarin in patients with atrial fibrillation. N Engl J Med 2009;361:1139-51.

16. Schulman S, Kearon C, Kakkar AK, et al. Dabigatran versus warfarin in the treatment of acute venous thromboembolism. N Engl J Med 2009;361:234252.

17. Schulman S, Kearon C, Kakkar AK, et al. RE-SONATE Trial Investigators. Extended use of dabigatran, warfarin, or placebo in venous thromboembolism. N Engl J Med 2013;368:709-18.

18. Eriksson BI, Dahl OE, Rosencher N, et al. RE-MODEL Study Group. Oral dabigatran etexilate vs subcutaneous enoxaparin for the prevention of venous thromboembolism after total knee replacement: the RE-MODEL randomized trial. J Thromb Haemost 2007;5:2178-85.

19. Eriksson BI, Dahl OE, Rosencher N, et al. Dabigatran etexilate versus enoxaparin for prevention of venous thromboembolism after total hip replacement: a randomised, double-blind, non-inferiority trial. Lancet 2007;370:949-56.

20. Eikelboom JW, Connolly SJ, Brueckmann M, et al. Dabigatran versus warfarin in patients with mechanical heart valves. $\mathrm{N}$ Engl $\mathrm{J}$ Med 2013;369:1206-14.

21. Aimo A, Giugliano RP, De Caterina R. Non-vitamin $\mathrm{K}$ antagonist oral anticoagulants for mechanical heart valves: is the door still open?. Circulation 2018;138:1356-65.

22. Connolly SJ, Crowther M, Eikelboom JW, et al. Full study report of andexanet alfa for bleeding associated with factor Xa inhibitors. N Engl J Med 2019;380:1326-35.

23. Patel MR, Mahaffey KW, Garg J, et al. 
Rivaroxaban versus warfarin in nonvalvular atrial fibrillation. N Engl J Med 2011;365:883-91.

24. EINSTEIN Investigators, Bauersachs $\mathrm{R}$, Berkowitz SD, et al. Oral rivaroxaban for symptomatic venous thromboembolism. N Engl J Med 2010;363:2499-510.

25. EINSTEIN-PE Investigators, Büller HR, Prins MH, et al. Oral rivaroxaban for the treatment of symptomatic pulmonary embolism. N Engl J Med 2012;366:1287-97.

26. Pengo V, Denas G, Zoppellaro G, et al. Rivaroxaban vs warfarin in high-risk patients with antiphospholipid syndrome. Blood 2018;132:1365-71.

27. Kakkos SK, Gohel M, Baekgaard N, et al. Editor's Choice - European Society for Vascular Surgery (ESVS) 2021 clinical practice guidelines on the management of venous thrombosis. Eur J Vasc Endovasc Surg 2021;61:9-82.

28. Eriksson BI, Borris LC, Friedman RJ, et al. Rivaroxaban versus enoxaparin for thromboprophylaxis after hip arthroplasty. N Engl J Med 2008;358:276575.

29. Kakkar AK, Brenner B, Dahl OE, et al. Extended duration rivaroxaban versus short-term Enoxaparin for the prevention of venous thromboembolism after total hip arthroplasty: a double-blind, randomised controlled trial. Lancet 2008;372:31-9.

30. Lassen MR, Ageno W, Borris LC, et al. Rivaroxaban versus enoxaparin for thromboprophylaxis after total knee arthroplasty. N Engl J Med 2008;358:2776-86.

31. Turpie AG, Lassen MR, Davidson BL, et al. Rivaroxaban versus enoxaparin for thromboprophylaxis after total knee arthroplasty (RECORD4): a randomised trial. Lancet 2009;373:167380.

32. Eikelboom JW, Connolly SJ, Bosch J, et al. Rivaroxaban with or without aspirin in stable cardiovascular disease. N Engl J Med 2017;377:1319-30.

33. Bonaca MP, Bauersachs RM, Anand $\mathrm{SS}$, et al. Rivaroxaban in peripheral artery disease after revascularization. N Engl J Med 2020;382:1994-2004.

34. Granger CB, Alexander JH, McMurray $\mathrm{JJ}$, et al. Apixaban versus warfarin in patients with atrial fibrillation. N Engl J Med 2011;365:981-92.

35. Connolly SJ, Eikelboom J, Joyner C, et al. Apixaban in patients with atrial fibrillation. N Engl J Med 2011;364:80617.

36. Lassen MR, Raskob GE, Gallus A, et al. Apixaban or enoxaparin for thromboprophylaxis after knee replacement. N Engl J Med 2009;361:594-604.

37. Lassen MR, Raskob GE, Gallus A, et al. Apixaban versus enoxaparin for thromboprophylaxis after knee replacement (ADVANCE-2): a randomized doubleblind trial. Lancet 2010;375:807-15.

38. Lassen MR, Gallus A, Raskob GE, et al. Apixaban versus enoxaparin for thromboprophylaxis after hip replacement. $\mathrm{N}$
Engl J Med 2010;363:2487-98.

39. Agnelli G, Buller HR, Cohen A, et al. Oral apixaban for the treatment of acute venous thromboembolism. N Engl J Med 2013;369:799-808.

40. Agnelli G, Buller HR, Cohen A, et al. Apixaban for extended treatment of venous thromboembolism. N Engl J Med 2013;368:699-708.

41. Stacy ZA, Call WB, Hartmann AP, et al. Edoxaban: a comprehensive review of the pharmacology and clinical data for the management of atrial fibrillation and venous thromboembolism. Cardiol Ther 2016;5:1-18.

42. Giugliano RP, Ruff CT, Braunwald E, et al. Edoxaban versus warfarin in patients with atrial fibrillation. $\mathrm{N}$ Engl $\mathrm{J}$ Med. 2013;369:2093-104.

43. Hokusai-VTE Investigators, Büller HR, Décousus $\mathrm{H}$, et al. Edoxaban versus warfarin for the treatment of symptomatic venous thromboembolism. N Engl J Med 2013;369:1406-15.

44. Raskob G, Ageno W, Cohen AT, et al. Extended duration of anticoagulation with edoxaban in patients with venous thromboembolism: a post-hoc analysis of the Hokusai-VTE study. Lancet Haematol 2016;3:e228-36.

45. Hindricks G, Potpara T, Dagres N, et al. 2020 ESC guidelines for the diagnosis and management of atrial fibrillation developed in collaboration with the European Association for CardioThoracic Surgery (EACTS). Eur Heart J 2021;42:373-498. 